\title{
Genetic and environmental aspects in the association between attention-deficit hyperactivity disorder symptoms and binge-eating behavior in adults: a twin study
}

\author{
A. J. Capusan ${ }^{1,2 *}$, S. Yao ${ }^{3}$, R. Kuja-Halkola ${ }^{3}$, C. M. Bulik ${ }^{3,4,5}$, L. M. Thornton ${ }^{4}$, P. Bendtsen ${ }^{6}$, \\ I. Marteinsdottir ${ }^{2}$, A. Thorsell ${ }^{2}$ and H. Larsson ${ }^{3,7}$ \\ ${ }^{1}$ Department of Psychiatry and Department of Clinical and Experimental Medicine, Linköping University, Sweden \\ ${ }^{2}$ Department of Clinical and Experimental Medicine, Center for Social and Affective Neuroscience (CSAN), \\ Linköping University, Linköping, Sweden \\ ${ }^{3}$ Department of Medical Epidemiology and Biostatistics, Karolinska Institutet, Stockholm, Sweden \\ ${ }^{4}$ Department of Psychiatry, University of North Carolina at Chapel Hill, Chapel Hill, USA \\ ${ }^{5}$ Department of Nutrition, University of North Carolina at Chapel Hill, Chapel Hill, USA \\ ${ }^{6}$ Department of Medical Specialist and Department of Medical and Health Sciences, Linköping University, Motala, Sweden \\ ${ }^{7}$ School of Medical Sciences, Örebro University, Örebro, Sweden
}

Background. Prior research demonstrated that attention-deficit hyperactivity disorder (ADHD) is associated with bingeeating behavior, binge-eating disorder (BED), and bulimia nervosa (BN). The aim of this study was to investigate these associations in an adult twin population, and to determine the extent to which ADHD symptoms and binge-eating behavior share genetic and environmental factors.

\begin{abstract}
Methods. We used self-reports of current ADHD symptoms and lifetime binge-eating behavior and associated characteristics from a sample of over 18000 adult twins aged 20-46 years, from the population-based Swedish Twin Registry. Mixed-effects logistic regression was used to examine the association between ADHD and lifetime binge-eating behavior, BED, and BN. Structural equation modeling was used in 13773 female twins to determine the relative contribution of genetic and environmental factors to the association between ADHD symptoms and binge-eating behavior in female adult twins.
\end{abstract}

Results. ADHD symptoms were significantly associated with lifetime binge-eating behavior, BED, and BN. The heritability estimate for current ADHD symptoms was 0.42 [95\% confidence interval (CI) 0.41-0.44], and for lifetime binge-eating behavior 0.65 (95\% CI $0.54-0.74)$. The genetic correlation was estimated as 0.35 (95\% CI $0.25-0.46)$ and the covariance between ADHD and binge-eating behavior was primarily explained by genetic factors (91\%). Non-shared environmental factors explained the remaining part of the covariance.

Conclusions. The association between adult ADHD symptoms and binge-eating behavior in females is largely explained by shared genetic risk factors.

Received 23 October 2016; Revised 24 April 2017; Accepted 3 May 2017; First published online 5 June 2017

Key words: ADHD, binge eating, bivariate twin analysis, heritability, twins.

\section{Introduction}

Attention-deficit hyperactivity disorder (ADHD), characterized by impairing hyperactivity/impulsivity and inattention often co-occurs with psychiatric and medical disorders (Kessler et al. 2006; Barkley et al. 2008). Epidemiological studies identified comorbidities

\footnotetext{
* Address for correspondence: A. J. Capusan, M.D., Ph.D., Department of Psychiatry and Department of Clinical and Experimental Medicine, Linköping University, SE-581 85 Linköping, Sweden.

(Email: Andrea.Johansson.Capusan@liu.se)
}

between ADHD and binge eating across the lifespan (Cortese et al. 2007a; Reinblatt et al. 2015). Binge eating is a key symptom in eating disorders such as bulimia nervosa (BN), binge-purge subtype of anorexia nervosa (AN), and binge-eating disorder (BED) (American Psychiatric Association, 2013). Prospective follow-up studies implicate childhood ADHD as a risk factor for conditions involving binge eating (Sonneville et al. 2015), binge-purge behaviors (Bleck \& DeBate, 2013), and BN (Mikami et al. 2008) in adolescence. Case-control studies revealed an increased risk for BN in women with ADHD, but not in children or males (Surman et al. 2006). Children in these studies 
were probably too young to have developed BN during the follow-up. Another study (Biederman et al. 2007) described increased risk for $B N$ and $A N$ in girls with ADHD v. controls. Conversely, increased risk for ADHD was found in clinical populations characterized by overeating and obesity across the lifespan, such as child psychiatric services, obese adults undergoing bariatric surgery (Cortese et al. 2007a, b; Davis et al. 2009a), or adults with BN (Seitz et al. 2013). Adult ADHD cases may differ from those with childhood onset (Moffitt et al. 2015), highlighting the importance of studying the association between ADHD symptoms and binge eating in adults.

ADHD and binge eating may implicate overlapping neurobehavioral circuits, involving problems with response inhibition, emotional regulation, and reward processing (Seymour et al. 2015). Binge eating, BN, and the binge-purge subtype of AN have been associated with behavioral impulsivity (Engel et al. 2005; Rosval et al. 2006), which is a key component in ADHD symptomatology. Genetically influenced behavioral traits such as delay aversion and low inhibitory control play a role in ADHD (Solanto et al. 2001; Sonuga-Barke \& Fairchild, 2012) and binge eating (Davis et al. 2010; Seymour et al. 2015). Individuals with both ADHD and binge eating may represent a subgroup with specific therapeutic needs. In order to develop effective prevention and treatment strategies, it is important to determine to what extent the overlap between ADHD and binge eating reflects shared genetic and/or environmental factors. Genetic factors were established for both ADHD, with heritability estimates ranging from $30-40 \%$ for self-reported data in adults to $60-90 \%$ for childhood and adult clinical samples (Franke et al. 2012; Larsson et al. 2013; Brikell et al. 2015), and for binge-eating behaviors and BEDs (heritability estimated between $41 \%$ and $70 \%$ ) (Bulik et al. 1998; Reichborn-Kjennerud et al. 2004; Bulik et al. 2010; Mitchell et al. 2010; Root et al. 2010; Trace et al. 2013a). No twin study has examined the genetic and environmental factors shared between ADHD symptoms and binge eating.

We examined the association between ADHD symptoms with lifetime binge-eating behavior, BED, and $\mathrm{BN}$, based on self-reported symptoms in a large adult twin population. We evaluated the extent to which the association between ADHD symptoms and bingeeating behavior is due to genetic and environmental factors using twin methods. The hyperactive/impulsive (HI) and inattentive (IN) symptom dimensions of ADHD co-vary (Willcutt et al. 2012) and share some genetic factors (McLoughlin et al. 2007; Larsson et al. 2013), but specific genetic influences for each symptom dimension have been identified (McLoughlin et al. 2007). Therefore, we examined separately how binge-eating behavior associates with $\mathrm{HI}$ and IN symptom dimensions.

\section{Methods and materials}

\section{Study population}

This study used data from the national Swedish Twin Registry, the Study of Twin Adults: Genes and Environment (Lichtenstein et al. 2006). The regional ethics committee of Karolinska Institutet, Stockholm, Sweden approved the project. All participants provided informed consent. From the target population of 42582 Swedish adult twins, born 1959-1985, $N=$ $25491(60 \%)$ responded. Participants received personal login to the study's website, containing a questionnaire on lifestyle, physical and mental health, described in earlier publications (Lichtenstein et al. 2002; Furberg et al. 2008; Friedrichs et al. 2012; Trace et al. 2012; Capusan et al. 2016). Non-responders received three reminders, and were offered the alternative of a telephone interview with a trained interviewer, and an additional self-administered paper questionnaire, instead of the web page. The total study population comprised $14184(55.6 \%)$ women, mean age $=33.6$ years (S.D. 7.6 years; range 20-46 years) and 11307 $(44.4 \%)$ men, mean age $=33.7$ years (s.D. 7.6 years; range 20-46 years); 23767 (93.2\%) individuals provided data on binge eating, 18168 (71.3\%) on ADHD symptoms, and 18029 (70.7\%) on both. A standard similarity questionnaire, validated with DNA analysis (Lichtenstein et al. 2002; Peterson et al. 2016), determined zygosity. As men had low prevalence for binge-eating behavior, with only one concordant $\mathrm{MZ}$ pair and no concordant DZ pairs, we included only females in the twin analysis; 14184 female twins in 10373 pairs (3811 complete and 6562 incomplete pairs with only data from one individual in the pair available). Zygosity was not possible to establish in 411 individuals (2.9\%) from 147 complete, 117 incomplete pairs. The sample included 13773 female twins: 7328 individuals (53.2\%) [4312 (31.3\%) MZ and 3016 (21.9\%) same sex DZ] from 3664 complete pairs and 6445 individuals $(46.8 \%)$ from incomplete pairs [950 MZ (6.9\%), $1073(7.8 \%)$ same sex DZ and 4422 (32.1\%) opposite sex DZ individuals].

\section{Measures}

\section{$A D H D$}

Current ADHD symptoms were assessed with the 18 items (nine $\mathrm{HI}$ and nine IN items) from the Diagnostic and Statistical Manual of Mental Disorders, Text revision (DSM-IV-TR) (American Psychiatric Association, 2000). Response options for all items were: 
$0=$ 'no', 1 = 'yes, to some extent', and 2= 'yes' (online Supplementary material). Re-assessment of a subsample $(n=54) 2$ years later with the Adult ADHD Self-Report Scale (ASRS) (Kessler et al. 2007) found strong a correlation, estimated to $0.63 \quad(p<0.0001)$ with the initial ADHD measures, indicating stability over time for ADHD symptoms (Larsson et al. 2013), corresponding with previous research on self-reported adult ADHD symptoms (Boomsma et al. 2010). Individuals with elevated ADHD scores also displayed co-morbidities similar to those found in clinical ADHD cases (Friedrichs et al. 2012).

For twin analysis, we used the sum of ADHD symptom scores. We also created two variables based on sum scores of the nine $\mathrm{HI}$ and the nine IN symptoms. For descriptive purposes, we created diagnosis-like cut-offs for ADHD using the norm-based approach proposed by Barkley et al. (2002), described in earlier studies (Friedrichs et al. 2012; Capusan et al. 2016). Using this method, participants scoring two standard deviations (2 S.D.) above the mean on the HI, IN, or both ADHD symptom scales were scored positive for ADHD.

\section{Binge-eating behavior}

Binge-eating behavior was assessed via self-report items based on the Structured Clinical Interview for DSM-IV-TR (SCID) (First et al. 2002). Questions had a 'branching' format: subsequent questions were only asked if participants answered yes to the first (gate) question/s in the section. See questions on binge eating and related disorders in online Supplementary material.

A lifetime history of binge-eating behavior was coded positive, if the participant answered yes to both having experienced eating binges and loss of control over food intake. Frequency and duration criteria were not required. We also evaluated binge-eating behavior using DSM-5 frequency and duration criteria (Trace et al. 2012): recurrent eating binges and loss of control at least four times/month for at least 3 months (DSM-5 binge-eating behavior).

Lifetime BED and BN were defined using self-report symptoms (SCID) based on DSM-5 criteria. BED was judged present if the participant reported binge eating at least four times/month for at least 3 months, without compensatory behaviors (self-induced vomiting, diet pills, diuretics, laxatives, exercise more than $2 \mathrm{~h}$ daily, not eating, or other methods to prevent weight gain when binge eating); endorsed at least three additional BED symptoms; and reported feeling distressed over binge eating. $\mathrm{BN}$ was defined as binge eating at least four times/month for at least 3 months, coupled with recurrent inappropriate compensatory behaviors in association with binge eating, and self-evaluation unduly influenced by body shape and weight.

\section{Statistical analysis}

Descriptive statistics were used to characterize the study population (Table 1). We used mixed-effects logistic regression, with a random effect shared between twins in the same pair, adjusted for sex and age at assessment, to calculate prevalence odds ratios (ORs) and 95\% confidence intervals (CIs), as measures of association between ADHD symptoms (2 s.D. cutoff) and binge-eating behavior, BED, and BN using Stata 11.2 (StataCorp LP, College Station, Texas, USA).

We used structural equation modeling to perform maximum-likelihood model-fitting with OpenMx (Boker et al. 2011) for ADHD symptoms and bingeeating behavior in female twins. This allows inclusion of individuals, with information from only one twin in a pair available. In opposite sex DZ twins, males' results were set as missing. We used the full information maximum likelihood method to handle missing data. We also fitted models using female-female pairs only, with results in line with current results (online Supplementary material). Low power prevented analysis of associations of ADHD symptoms with BED and BN.

Individuals from MZ twin pairs share $100 \%$, while DZ pairs share, on average, $50 \%$ of their segregating genes. MZ and DZ twins are assumed to share family environment equally. Higher twin correlations (within twin pair correlation for a given trait) for $\mathrm{MZ}$ compared with DZ twins indicate the role of additive genetic factors (A), reflecting additive effects of different alleles; MZ correlations greater than twice the DZ correlations indicate non-additive effects (dominance, D), reflecting interaction effects between alleles at the same genetic locus. DZ correlations greater than half the MZ correlations suggest an effect of shared environment (C), i.e. environmental factors common to both twins. $\mathrm{MZ}$ correlations lower than 1 indicate the role of nonshared environmental effects (E), i.e. environmental factors acting to make twins different, including measurement error. Cross-twin, cross-trait correlations (CTCT) - the correlation between twin 1's status on ADHD and twin 2's status on binge-eating behavior, and vice versa - can indicate genetic and/or environmental factors shared between the two traits. All models were adjusted for age at time of assessment, used as a covariate.

We applied structural equation modeling to estimate how much the variance of ADHD symptoms, bingeeating behavior, and the covariance between them, was explained by A, C, D, and E. Different models were fitted to the data, including models limited to 
Table 1. Distribution of binge-eating behavior, DSM-5 binge eating, BED, and BN in the population and ADHD symptoms (norm-based 2 s.D. method) in Swedish adult twins

\begin{tabular}{|c|c|c|c|c|c|}
\hline & $\begin{array}{l}\text { Total responders } \\
\text { for binge-eating } \\
\text { variables }\end{array}$ & $\begin{array}{l}\text { Number who } \\
\text { endorsed } \\
\text { binge-eating } \\
\text { variables } n(\%)\end{array}$ & $\begin{array}{l}\text { Total responders for } \\
\text { ADHD symptoms } \\
\text { and binge eating } \\
\text { variables } N\end{array}$ & $\begin{array}{l}\text { Positive for ADHD } \\
\text { symptoms }{ }^{1} n_{1} \\
(\% \text { of total } N)\end{array}$ & $\begin{array}{l}\text { Positive for } \\
\text { binge-eating variables } \\
\text { in those positive for } \\
\text { ADHD symptoms } n_{2} \\
\left(\% \text { of } n_{1}\right)^{2}\end{array}$ \\
\hline \multicolumn{6}{|c|}{ Binge-eating behavior $^{3}$} \\
\hline Total & 23767 & $639(2.69)$ & 18029 & $1575(8.74)$ & $113(7.17)$ \\
\hline Male & 10419 & $54(0.52)$ & 7244 & $629(8.68)$ & $13(2.07)$ \\
\hline Female & 13348 & $585(4.38)$ & 10785 & $946(8.77)$ & $100(10.57)$ \\
\hline \multicolumn{6}{|c|}{ DSM-5 binge eating ${ }^{4}$} \\
\hline Total & 23673 & $355(1.50)$ & 17948 & $1559(8.69)$ & $58(3.72)$ \\
\hline Male & 10410 & $21(0.20)$ & 7238 & $626(8.65)$ & $2(0.32)$ \\
\hline Female & 13263 & $334(2.52)$ & 10710 & $933(8.71)$ & $56(6.0)$ \\
\hline \multicolumn{6}{|l|}{$\mathrm{BED}^{5}$} \\
\hline Total & 23671 & $43(0.18)$ & 17947 & $1559(8.69)$ & $7(0.45)$ \\
\hline Male & 10410 & $4(0.04)$ & 7238 & $626(8.65)$ & $0(0)$ \\
\hline Female & 13261 & $39(0.29)$ & 10709 & $933(8.71)$ & $7(0.75)$ \\
\hline \multicolumn{6}{|l|}{$\mathrm{BN}^{5}$} \\
\hline Total & 23377 & $277(1.18)$ & 17778 & $1543(8.68)$ & $48(3.11)$ \\
\hline Male & 10276 & $12(0.12)$ & 7167 & $617(8.61)$ & $2(0.32)$ \\
\hline Female & 13101 & $265(2.02)$ & 10611 & $926(8.73)$ & $46(4.97)$ \\
\hline
\end{tabular}

BED, binge-eating disorder; BN, bulimia nervosa; ADHD, attention-deficit hyperactivity disorder; 2 s.D., 2 standard deviations; DSM-5, Diagnostic and Statistical Manual of Mental Disorders, Fifth edition.

${ }^{1}$ ADHD symptoms, norm-based, 2 s.D. cut-off method.

${ }^{2}$ Per cent of those positive for ADHD symptoms.

${ }^{3}$ Binge eating ever, with concomitant loss of control required, no duration and frequency restrictions.

${ }^{4}$ Binge eating for at least 3 months, at least four times/month.

${ }^{5} \mathrm{BED}$ and $\mathrm{BN}$ based on DSM-5 criteria.

components A, C, and E (ACE model); A, D, and E (ADE model); and A and E (AE model) (Neale \& Cardon, 1992). Based on previous research and on the observed twin correlations in our sample, all fitted models included additive genetic components. Models were compared with a saturated model (i.e. all means and covariance matrices were allowed to differ for different types of twins) using a likelihood ratio $\chi^{2}$ test. This test can indicate if the model fits the data significantly worse than the fully saturated model. To identify the best-fitting model, we also computed the Akaike Information Criterion (AIC). Lower AIC values indicate better quality of the model for observed data. As AIC favors parsimony, models with fewer parameters adequately explaining the data are favored (Table 2).

ADHD symptom count was a continuous variable, while binge-eating behavior was a binary variable. We used a liability-threshold approach, assuming an underlying normally distributed liability to bingeeating behavior. With this method, observed bingeeating behavior was 1 if the liability was above a threshold and 0 (no binge-eating behavior) if below. The phenotypic correlation refers to the correlation between ADHD symptoms and this underlying liability to binge-eating behavior. We used a univariate ACE model, to estimate heritability for ADHD-symptoms and binge-eating behavior and a bivariate-correlated factors model to estimate additive genetic $\left(r_{\mathrm{A}}\right)$, shared environmental $\left(r_{\mathrm{C}}\right)$, and non-shared environmental $\left(r_{\mathrm{E}}\right)$ correlations between ADHD and binge-eating behavior. Similarly, in an ADE model, we estimated $r_{\mathrm{A}}$, dominant genetic $\left(r_{\mathrm{D}}\right)$, and $r_{\mathrm{E}}$ correlations, and in the $\mathrm{AE}$ model $r_{\mathrm{A}}$ and $r_{\mathrm{E}}$. These correlations indicate the extent to which genetic and environmental influences on one measure correlate with those on the other. We also calculated the proportion of the phenotypic correlation between ADHD and binge-eating behavior explained by genetic and environmental factors. In a Cholesky decomposition (Fig. 1a), the ordering of the variables is important; the variable to the left is allowed to explain variance in variables to the right, but not vice versa. Consequently, factor A1 stands for the genetic factors for one trait (ADHD in this case), including 
Table 2. Quantitative genetic model fitting for ADHD symptoms, binge-eating behavior in Swedish female twins (males set as missing), compared with the saturated model

\begin{tabular}{|c|c|c|c|c|}
\hline & $\begin{array}{l}-2 \times \log \\
\text { likelihood }\end{array}$ & $\begin{array}{l}\text { Degrees } \\
\text { of } \\
\text { freedom }\end{array}$ & $\mathrm{AIC}^{1}$ & $p$ value $^{2}$ \\
\hline \multicolumn{5}{|c|}{ Univariate model } \\
\hline \multicolumn{5}{|c|}{ ADHD } \\
\hline Saturated & 62861.39 & 10630 & 41601.39 & NA \\
\hline $\mathrm{ACE}$ & 62868.67 & 10636 & 41596.67 & 0.30 \\
\hline $\mathrm{ADE}$ & 62869.16 & 10636 & 41597.16 & 0.26 \\
\hline $\mathrm{AE}$ & 62869.16 & 10637 & 41595.16 & 0.35 \\
\hline \multicolumn{5}{|c|}{ Binge-eating behavior } \\
\hline Saturated & 4534.44 & 13022 & -21509.6 & NA \\
\hline $\mathrm{ACE}$ & 4535.41 & 13025 & -21514.6 & 0.81 \\
\hline $\mathrm{ADE}$ & 4535.31 & 13025 & -21514.7 & 0.83 \\
\hline $\mathrm{AE}$ & 4535.41 & 13026 & -21516.6 & 0.91 \\
\hline \multicolumn{5}{|c|}{ Bivariate model (ADHD and binge-eating behavior) } \\
\hline Saturated & 67255.39 & 23644 & 19967.39 & NA \\
\hline $\mathrm{ACE}$ & 67281.18 & 23658 & 19965.18 & 0.03 \\
\hline ADE & 67281.94 & 23658 & 19965.94 & 0.02 \\
\hline $\mathrm{AE}$ & 67282.07 & 23661 & 19960.07 & 0.06 \\
\hline
\end{tabular}

A, additive genetic factors; $\mathrm{D}$, dominant genetic factors; $C$, shared environmental factors; $E$, non-shared environmental factors; ADHD, attention-deficit hyperactivity disorder.

${ }^{1}$ AIC - Akaike Information Criterion. Lowest AIC, indicating the best fitting model is highlighted in bold.

${ }^{2} p$ value (compared with the saturated model).

those shared with the other trait (binge-eating behavior). A significant path a12 will indicate shared genetic effects. A2 are the unique (residual) genetic factors for binge-eating behavior, and vice versa for ADHD if the order of the variables is reversed. For simplicity, Fig. $1 a$ and $b$ only illustrate genetic factors, but environmental factors were modelled using the same pattern.

Further we examined how binge-eating behavior was associated with $\mathrm{HI}$ and IN ADHD symptom dimensions, respectively, using bivariate models. In both sets of analyses, phenotypic correlations, intraclass correlations and CTCT adjusted for age at assessment were estimated, similar to the main analysis. In order to determine if genetic or environmental effects shared with binge-eating behavior were specific to $\mathrm{HI}$ or IN symptoms, we fitted two separate trivariate models (Cholesky decomposition): first a model to estimate phenotypic correlation between $\mathrm{HI}$ and binge-eating behavior when controlling for IN (partial correlation), and second the partial correlation between IN and binge-eating behavior when controlling for HI. Similarly, we estimated genetic and non-shared environmental correlations between $\mathrm{HI}$ and binge-eating behavior when controlling for IN and vice-versa for
IN, controlling for HI. In the trivariate model, the factor $\mathrm{A} 1 \mathrm{in}$ Fig. $1 b$ represents genetic factors in common for HI, IN, and binge-eating behavior. Factor A2 captures additional factors unique to IN and shared with binge-eating behavior. A significant path between A2 and binge-eating behavior, labeled a23 in Fig. $1 b$, indicates effects associated with IN (but not $\mathrm{HI}$ ) shared with binge-eating behavior. Similarly, genetic effects shared between HI (but not IN) and binge-eating behavior can be calculated, setting IN first in the model.

\section{Results}

Table 1 displays descriptive statistics for binge-eating behavior in the population by sex and by ADHD symptom status. The prevalence of binge-eating behavior was low. Of 23767 individuals providing data, 639 $(2.69 \%)$, males $=54(0.52 \%)$ and females $=585(4.38 \%)$, reported lifetime binge-eating behavior. $N=43(0.18 \%)$ endorsed symptoms meeting criteria for BED, and $n=277(1.18 \%)$ for BN. Low prevalence in males decreased the population prevalence (Table 1).

Those with ADHD symptoms (2 s.D. cut-off) had significantly increased risk for binge-eating behavior [OR 3.65 (95\% CI 2.72-4.91), $p<0.001$ ] and DSM-5 binge-eating behavior [OR 3.01 (95\% CI 2.09-4.35), $p<0.001$ ] compared with those without ADHD symptoms. Both BED [OR 2.55 (95\% CI 1.11-5.86), $p<0.05$ ] and BN [OR 3.09 (95\% CI 2.09-4.56), $p<0.001)$ ] were significantly more common in adults with ADHD symptoms (online Supplementary material).

Subsequent analysis focused on binge-eating behavior in female twins only. We observed a statistically significant phenotypic correlation of $0.20(95 \% \mathrm{CI}$ 0.15-0.26) between ADHD symptom count and binge-eating behavior. Twin correlations and CTCT correlations indicated genetic factors contributing to ADHD symptoms, binge-eating behavior, and the covariance between the two phenotypes (online Supplementary material).

Univariate model fitting for ADHD and for binge-eating behavior indicated $\mathrm{AE}$ as best fitting models, not significantly different from the saturated models and with lowest AIC values (Table 2). Univariate analysis showed moderate heritability for ADHD (0.42, 95\% CI 0.41-0.44) and high heritability for binge-eating behavior $(0.65,95 \%$ CI $0.54-0.74)$. Bivariate model fitting also indicated $\mathrm{AE}$ as the best fitting model. The genetic correlation was estimated at 0.28 (95\% CI $0.17-0.40)$ and the non-shared environmental correlation at $0.10(95 \%$ CI -0.04 to 0.24). Shared genetic factors explained $91 \%$ of the covariance between ADHD and binge-eating behavior. Non-shared environmental effects (E) accounted for 
(a)

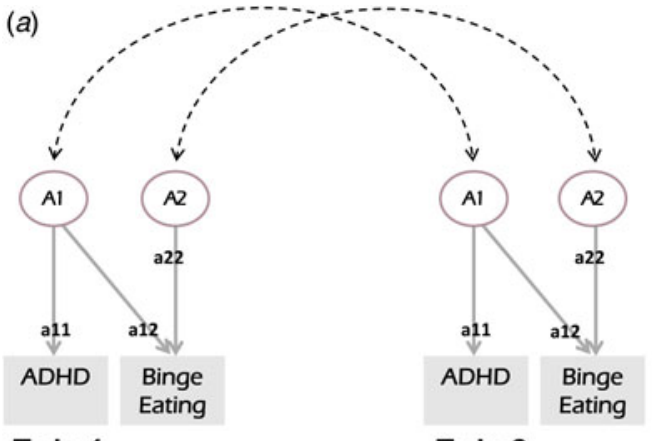

Twin 1

Twin 2

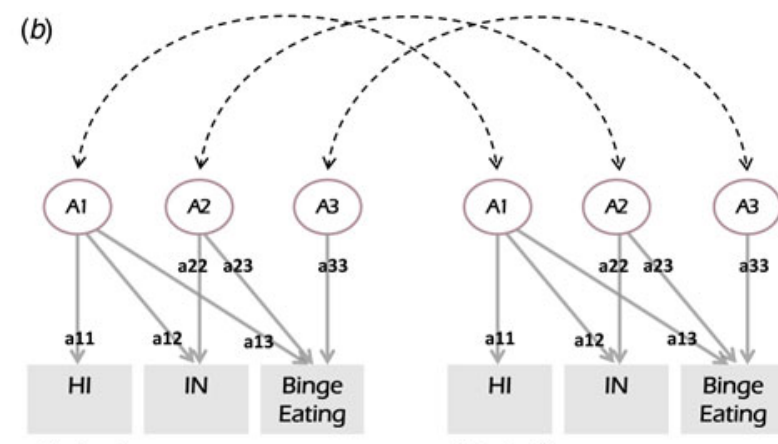

Twin 1

Twin 2

Fig. 1. (a) Bivariate Cholesky decomposition of genetic factors shared by ADHD and binge-eating behavior. A1=genetic factors for ADHD and shared with binge-eating behavior (path a12), A2 = residual (unique) genetic factors for binge-eating behavior (when binge eating is set second in the model). (b) Trivariate Cholesky decomposition of unique genetic factors shared by IN and binge-eating behavior when controlling for common factors for HI, IN, and binge-eating behavior. A1 = factors in common between IN and HI shared with binge-eating behavior, A2 = additional factors unique to IN shared with binge-eating behavior. HI, hyperactive impulsive adult ADHD symptoms; IN, inattentive adult ADHD symptoms and binge-eating behavior (when binge eating is set second in the model); ADHD, attention-deficit hyperactivity disorder.

the remaining $9 \%$ of the covariance (Table 3). Figure 2 shows the proportion of shared $v$. residual (unique) genetic and environmental effects explaining the variability of each phenotype (ADHD respectively binge eating).

We analyzed separately how binge-eating behavior was associated with $\mathrm{HI}$ and IN ADHD symptom dimensions. Phenotypic correlations between bingeeating behavior and both $\mathrm{HI}(0.18,95 \%$ CI $0.12-0.24)$ and IN $(0.18,95 \%$ CI $0.13-0.24)$ symptoms were similar. CTCT indicated shared genetic factors for both HI and IN with binge-eating behavior (online Supplementary material). The partial correlation between binge-eating behavior and the IN symptom dimension when controlling for $\mathrm{HI}(0.10,95 \%$ CI $0.06-0.13)$ was stronger than the partial correlation between binge-eating behavior and the HI symptom dimension $(0.03,95 \%$ CI -0.01 to 0.07 ) (Table 4). Genetic correlation for the IN symptoms and binge-eating behavior remained statistically significant when controlling for factors shared with $\mathrm{HI}(0.28,95 \% \mathrm{CI} 0.13-0.42)$. In contrast, genetic and environmental correlations between the HI symptom dimension and binge eating attenuated substantially and became non-significant, when controlling for factors shared with IN.

\section{Discussion}

This study explored the association between ADHD symptoms in adults and lifetime binge-eating behavior in a population-based sample of twins. Shared genetic factors explained most of this association in females. Future genomic studies for ADHD and binge eating should focus on identifying such shared cross-disorder genetic risks. Better understanding of the nature of associations between ADHD and binge eating is useful when developing novel early intervention strategies and, thereby, possibly preventing the adverse correlates of binge eating, such as obesity, anxiety, depression, and suicidal risk (Davis, 2015; Welch et al. 2016).

\section{Phenotypic associations}

Like previous studies (Surman et al. 2006; Cortese et al. 2007b; Bleck \& DeBate, 2013), we found ADHD symptoms in adults significantly associated with increased binge-eating behavior, as well as with BED and BN. Results are in accord with follow-up studies identifying childhood ADHD as risk factor for binge eating (Biederman et al. 2007; Bleck \& DeBate, 2013; Sonneville et al. 2015). The lower prevalence of BED and BN in our population compared with other studies may partly be due to low prevalence in males and partly to geographical differences. A recent Finnish study estimated BED prevalence to $0.7 \%$ (Mustelin et al. 2015), closer to our results and in contrast to US data suggesting BED prevalence around 3\% (Davis, 2015). Further studies are necessary to determine the prevalence of binge-eating behaviors and disorders and their association with clinically diagnosed ADHD. We found a considerable sex difference, with lower prevalence of binge-eating behaviors in men. Eating disorders are less common in men, but men may also under-report binge-eating symptoms due to feelings of shame and fear of stigmatization (Strother et al. 2012; MacLean et al. 2015). Other approaches are necessary, such as using clinical samples in primary health care and psychiatry or questionnaires adapted to how men experience eating disorders 
Table 3. Parameter estimates $\left(95 \% C I^{1}\right.$ ) for ACE, ADE and AE univariate models for ADHD symptoms; binge-eating behavior; and from bivariate model for ADHD and binge-eating behavior (binge eating) in a population of 13773 adult Swedish female twins (3664 complete twin pairs)

\begin{tabular}{|c|c|c|c|c|c|c|c|c|c|c|c|c|}
\hline & A2 & C2 & D2 & E2 & $r_{\mathrm{A}}$ & $r_{\mathrm{C}}$ & $r_{\mathrm{D}}$ & $r_{\mathrm{E}}$ & Bivariate $^{2} \mathrm{~A} 2$ & Bivariate $^{2} \mathrm{C} 2$ & Bivariate $^{2}$ D2 & Bivariate $^{2}$ E2 \\
\hline \multicolumn{13}{|l|}{$\mathrm{ACE}$} \\
\hline ADHD & $0.37(0.24,0.46)$ & $0.05(0.05,0.05)$ & & $0.58(0.54,0.61)$ & & & & & & & & \\
\hline Binge eating & $0.62(0.25,0.74$ & $0.03(0.01,0.33)$ & & $0.35(0.26,0.47)$ & & & & & & & & \\
\hline $\begin{array}{l}\text { ADHD and } \\
\text { binge eating }\end{array}$ & & & & & $\begin{array}{l}0.46 \\
\quad(0.15,0.96)\end{array}$ & $\begin{array}{l}-1 \\
(-1 \text { to }-1)\end{array}$ & & $\begin{array}{l}0.03 \\
(-0.08 \text { to } 0.15)\end{array}$ & $\begin{array}{l}1.01 \\
(0.31,1.76)\end{array}$ & $\begin{array}{l}-0.17 \\
(-0.70 \text { to } 0.50)\end{array}$ & & $\begin{array}{l}0.07 \\
(-0.19 \text { to } 0.33)\end{array}$ \\
\hline \multicolumn{13}{|l|}{$\mathrm{ADE}$} \\
\hline ADHD & $0.42(0.25,0.46)$ & & $0.01(0.01,0.01)$ & $0.58(0.54,0.61)$ & & & & & & & & \\
\hline Binge eating & $0.52(0,0.74)$ & & $0.13(0.00,0.73)$ & $0.35(0.25,0.46)$ & & & & & & & & \\
\hline $\begin{array}{l}\text { ADHD and } \\
\text { binge eating }\end{array}$ & & & & & $\begin{array}{l}0.34 \\
(1.00 \text { to }-1.00)\end{array}$ & & ${ }^{1}(-1$ to 1$)$ & $\begin{array}{l}0.04 \\
(-0.07 \text { to } 0.15)\end{array}$ & $\begin{array}{l}0.77 \\
(-0.41 \text { to } 1.16)\end{array}$ & & $\begin{array}{l}0.14 \\
(0.00,1.35)\end{array}$ & $\begin{array}{l}0.09 \\
(-0.17 \text { to } 0.34)\end{array}$ \\
\hline \multicolumn{13}{|l|}{$\mathrm{AE}$} \\
\hline ADHD & $0.42(0.41,0.44)$ & & & $0.58(0.56,0.60)$ & & & & & & & & \\
\hline Binge eating & $0.65(0.54,0.74)$ & & & $0.35(0.26,0.46)$ & & & & & & & & \\
\hline $\begin{array}{l}\text { ADHD and } \\
\text { binge eating }\end{array}$ & & & & & $\begin{array}{l}0.35 \\
\quad(0.25,0.46)\end{array}$ & & & $\begin{array}{l}0.04 \\
(-0.07 \text { to } 0.16)\end{array}$ & $\begin{array}{l}0.91 \\
\quad(0.66,1.16)\end{array}$ & & & $\begin{array}{l}0.09 \\
(-0.16 \text { to } 0.34)\end{array}$ \\
\hline
\end{tabular}

A, additive genetic factors; D, dominant genetic factors; C, non-shared environmental factors; E, non-shared environmental factors; ADHD, attention-deficit hyperactivity disorder.

${ }^{1} 95 \%$ confidence interval.

${ }^{2}$ Bivariate A (bivariate heritability) refers to the amount of covariance between the two phenotypes explained by A, similarly for C, D, and E. Best fitting model for the bivariate analysis is highlighted in bold. 


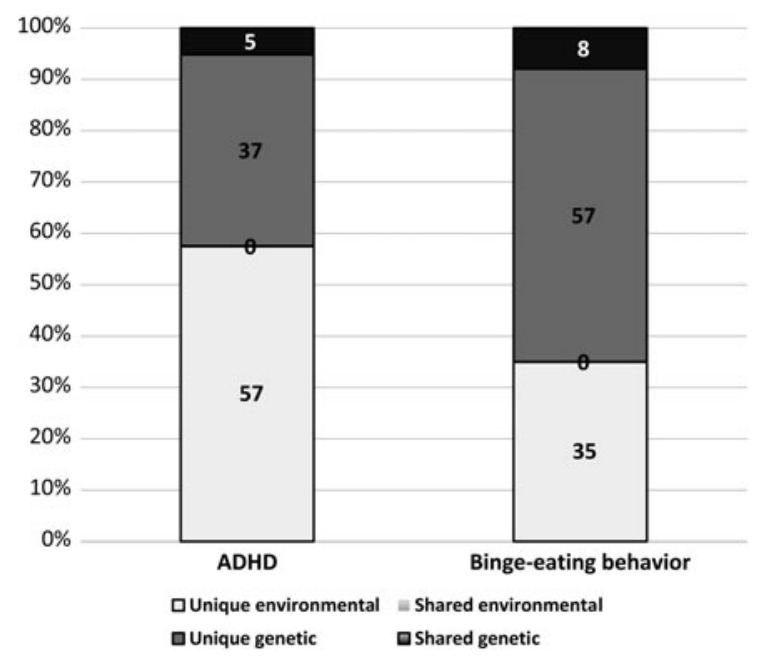

Fig. 2. Proportion of shared $v$. residual (unique) genetic and environmental effects explaining the variability of ADHD, when binge-eating behavior is set first in the model (Cholesky decomposition), respectively, of binge-eating behavior when ADHD is set first in the model. ADHD, attention-deficit hyperactivity disorder.

(Anderson \& Bulik, 2004), to investigate binge eating and related problems in males.

\section{Shared genetic and environmental factors}

Our results suggest the association between ADHD symptoms and binge-eating behavior being primarily due to shared genetic factors. Part of this genetic overlap may reflect genetic risk variants with general effects cutting across traditional boundaries between neuropsychiatric traits and disorders (Pettersson et al. 2016). Identification of cross-disorder genetic risks is one of the challenges to understanding the etiology of neuropsychiatric disorders.

The finding of shared genetic risk factors may also partly reflect shared neurocognitive underpinnings of ADHD and binge eating (Seymour et al. 2015). These involve problems with executive and cognitive function, and emotional regulation, such as negative urgency (Racine et al. 2013). Individuals with ADHD also display deficits in inhibitory control, vigilance, planning (Carmona et al. 2012; Coghill et al. 2014), and emotional regulation (Shaw et al. 2014), leading to suboptimal decision-making and preference for immediate $v$. delayed rewards (Solanto et al. 2001; Sonuga-Barke \& Fairchild, 2012). Deficits in inhibitory control and preference for immediate rewards are also exhibited in individuals with binge-eating behaviors, BN, binge-purge AN (Brogan et al. 2010; Wu et al. 2013), and BED (Davis et al. 2010). Dopamine (DRD2) receptor variability has been described in obese individuals with BED (Davis et al. 2009b) and in ADHD
(Franke et al. 2012), suggesting possible genetic overlap. Also dopamine D3 receptor implicated in $\mathrm{HI}$ ADHD symptoms and binge eating may have a role in the association (Davis et al. 2009a).

Another mechanism may involve the addictive potential of highly palatable foods (such as sweet and fatty and salty and fatty foods) that, similarly to psychoactive substances, activate dopamine release in mesolimbic reward pathways, increasing the risk for overeating (Gearhardt et al. 2011a; Schulte et al. 2016). Several studies suggest an addictive dimension to obesity (Volkow et al. 2013) and BED (Gearhardt et al. 2011b). Common genetic factors have been identified for BN (involving binge eating) and alcoholism (Trace et al. 2013b) as well as between ADHD and alcoholism (Edwards \& Kendler, 2012; Capusan et al. 2015). It could be speculated that shared genetic factors of ADHD symptoms and binge eating may partly reflect common genetic pathways for different addictive behaviors (Blum et al. 2000). Genetically influenced traits such as delay aversion and low inhibitory control were found in individuals with ADHD (Solanto et al. 2001; Sonuga-Barke \& Fairchild, 2012) and females with binge eating and related disorders (Davis et al. 2010; Wu et al. 2013). These may be particularly detrimental in environments with pervasive food-related cues, and with highly palatable foods easily available at all times (Davis et al. 2009b; Gearhardt et al. 2011b). The role of food-related addictive behaviors in binge eating and the association with ADHD needs further exploration in clinical samples.

In addition, overlap between ADHD and bingeeating behavior may also reflect ADHD dimensionspecific genetic effect. We found a small but significant genetic correlation between the IN symptoms and binge-eating behavior, even after controlling for the genetic effects shared with HI symptoms. There was however no evidence supporting specific genetic effects for the HI symptom dimension. This is somewhat surprising given that $\mathrm{HI}$ in girls has been associated with eating problems later in life (Mikami et al. 2008). In our study, we analyzed the association between ADHD symptoms in adults and binge eating. $\mathrm{HI}$ symptoms tend to decrease at a higher rate with age compared with IN symptoms (Biederman et al. 2000). We have no information on whether women reporting mainly IN symptoms, had more HI symptoms in their childhood. Future genomic studies on the association between ADHD and binge eating may benefit from including information about ADHD symptom dimensions and/or subtypes.

In the univariate analysis, $42 \%$ heritability estimate for ADHD is in line with previous twin studies based on self-report data (Boomsma et al. 2010; Franke et al. 2012), but lower than heritability estimates for 
Table 4. Association between HI ADHD symptoms and binge-eating behavior, when controlling for IN, and associations between IN and binge-eating behaviors when controlling for $\mathrm{HI}$

\begin{tabular}{|c|c|c|c|c|}
\hline & \multicolumn{2}{|c|}{$\begin{array}{l}\text { Association between } \mathrm{HI} \text { and } \\
\text { binge-eating behavior when } \\
\text { controlling for IN: }\end{array}$} & \multicolumn{2}{|c|}{$\begin{array}{l}\text { Association between IN and } \\
\text { binge-eating behavior when } \\
\text { controlling for } \mathrm{HI}\end{array}$} \\
\hline & Estimate & $(95 \% \mathrm{CI})$ & Estimate & $(95 \% \mathrm{CI})$ \\
\hline Partial correlation & 0.03 & $(-0.01$ to 0.07$)$ & 0.10 & $(0.06-0.13)$ \\
\hline Genetic correlation & 0.03 & $(-0.14$ to 0.18$)$ & 0.28 & $(0.13-0.42)$ \\
\hline Environmental correlation & 0.05 & $(-0.06$ to 0.16$)$ & 0.00 & $(-0.10$ to 0.11$)$ \\
\hline
\end{tabular}

HI, hyperactive/impulsive ADHD symptoms; IN, inattentive ADHD symptoms; 95\% CI, 95\% confidence interval; ADHD, attention-deficit hyperactivity disorder.

childhood ADHD and clinically diagnosed adult ADHD (around 60-90\%) (Larsson et al. 2014). Differences in heritability estimates have previously been attributed to rater effects (Brikell et al. 2015) and measurement error in self-report data (Franke et al. 2012). However, molecular genetic studies show similar polygenic risks (Levy et al. 1997; Martin et al. 2014) in clinical ADHD samples as for those associated with ADHD symptoms in the population, supporting the use of population samples for the study of ADHD (Faraone et al. 2015). For binge-eating behavior, heritability was estimated as $65 \%$, which is higher than one Norwegian study $\left[\begin{array}{llll}41 \% & (95 \% & C I & 31-50 \%)\end{array}\right.$ (Reichborn-Kjennerud et al. 2004)], but in line with another study assessing binge eating in women [70\% (95\% CI 26-77\%) (Root et al. 2010)].

\section{Limitations}

Presented results should be considered in the context of several limitations. Response rates of $60 \%$, similar to other large epidemiological surveys, were relatively low. Drop-out has previously been attributed to unwillingness to answer to a survey with over 1300 questions. Drop-out analyses, described earlier (Furberg et al. 2008; Friedrichs et al. 2012; Larsson et al. 2013), found that non-responders did not significantly differ from responders regarding birth weight and age; however, non-responders were significantly more often male, had a parent/s born outside of Sweden, had been diagnosed with a psychiatric condition, and convicted for any type of crime. As ADHD is associated with psychiatric disorders (Kessler et al. 2006), and is more prevalent in prison populations (Edvinsson et al. 2010; Ginsberg et al. 2010), individuals with more severe ADHD probably did not respond to the questionnaire, limiting generalizability of our findings to the more severe end of the ADHD spectrum.
All data were based on self-reported symptoms in the general population. Self-reported ADHD symptoms show satisfactory psychometric properties (Murphy \& Schachar, 2000; Sandra Kooij et al. 2008), and were found to be stable over time (Larsson et al. 2013). Information on functional impairment or childhood onset was not available. Our sample probably includes subthreshold cases, with ADHD symptoms, without fulfilling criteria for a clinical diagnosis that may be the less severe manifestations of the syndrome (Faraone et al. 2006).

Reliability of self-reported data on binge eating and related conditions is more unclear. An earlier twin study found low reliability and lower heritability estimates, around 50\% (Bulik et al. 1998) for binge eating reported by just one assessment. Described results reflect an association between ADHD symptoms and binge-eating behavior, in about half of the cases outside DSM-5 BED and BN cut-offs. Given the low prevalence in our sample compared with international findings, it is likely that binge eating was underreported and our measures are conservative, probably restricting generalizability to the milder end of the spectrum in the population.

Heritability estimates were based on only eight female DZ twins concordant for binge-eating behavior, possibly affecting precision of our estimates. Despite a large study population, statistical power was too low to examine genetic and environmental aspects of the association in males, which is an important limitation and calls for future research using alternative methodologies that more accurately capture symptom patterns in males and could therefore yield different results.

Although we assess lifetime binge eating, ADHD is assessed as current symptoms. As data are crosssectional, we are not able to draw any inference regarding whether ADHD leads to binge eating in adults. Longitudinal follow-up research found that ADHD in children and adolescents is a risk factor for later 
binge eating (Biederman et al. 2007; Bleck \& DeBate, 2013; Sonneville et al. 2015). Further longitudinal clinical studies are necessary to elucidate the temporal nature of the association between ADHD and binge eating in adults.

Results may also be influenced by inherent limitations in twin studies. For instance, basic assumptions in twin studies include random mating in the population. Assortative mating in some psychiatric conditions, including ADHD (Nordsletten et al. 2016) may lead to underestimating heritability. Conversely, gene-environment interactions between the easy availability of highly palatable foods and genetically determined characteristics, such as reduced inhibitory control or emotional dysregulation in individuals with ADHD, cannot be excluded. In a twin study, these effects would be subsumed in the heritability estimates, possibly overestimating common genetic factors in bivariate models.

In conclusion, this study suggests that the association between adult ADHD symptoms and lifetime binge-eating behavior is primarily due to shared genetic risk factors in females. Clinicians need to be aware of these associations when assessing and managing individuals presenting with ADHD symptoms or binge-eating behavior.

\section{Supplementary Material}

The supplementary material for this article can be found at https://doi.org/10.1017/S0033291717001416.

\section{Acknowledgements}

A.J.C. has received ALF Grants, Region Östergötland, Sweden (LIO-440851). C.M.B. acknowledges funding from the Swedish Research Council (VR Dnr: 5382013-8864). S.Y. acknowledges financial support from China Scholarship Council.

\section{References}

American Psychiatric Association (2000). Diagnostic and Statistical Manual of Mental Disorders, 4th edn, DSM-IV-TR, American Psychiatric Press: Washington, DC.

American Psychiatric Association (2013). Diagnostic and Statistical Manual of Mental Disorders: DSM-5. American Psychiatric Press: Washington, DC.

Anderson CB, Bulik CM (2004). Gender differences in compensatory behaviors, weight and shape salience, and drive for thinness. Eating Behaviors 5, 1-11.

Barkley RA, Fischer M, Smallish L, Fletcher K (2002). The persistence of attention-deficit/hyperactivity disorder into young adulthood as a function of reporting source and definition of disorder. Journal of Abnormal Psychology 111, 279-289.

Barkley RA, Murphy KR, Fischer M (2008). ADHD in Adults: What the Science Says. Guilford Press: New York.

Biederman J, Ball SW, Monuteaux MC, Surman CB, Johnson JL, Zeitlin S (2007). Are girls with ADHD at risk for eating disorders? Results from a controlled, five-year prospective study. Journal of Developmental and Behavioral Pediatrics 28, 302-307.

Biederman J, Mick E, Faraone SV (2000). Age-dependent decline of symptoms of attention deficit hyperactivity disorder: impact of remission definition and symptom type. American Journal of Psychiatry 157, 816-818.

Bleck J, Debate RD (2013). Exploring the co-morbidity of attention-deficit/hyperactivity disorder with eating disorders and disordered eating behaviors in a nationally representative community-based sample. Eating Behaviors 14, 390-393.

Blum K, Braverman ER, Holder JM, Lubar JF, Monastra VJ, Miller D, Lubar JO, Chen TJ, Comings DE (2000). Reward deficiency syndrome: a biogenetic model for the diagnosis and treatment of impulsive, addictive, and compulsive behaviors. Journal of Psychoactive Drugs 32 (Suppl. 1), 1-112.

Boker S, Neale M, Maes H, Wilde M, Spiegel M, Brick T, Spies J, Estabrook R, Kenny S, Bates T, Mehta P, Fox J (2011). OpenMx: an open source extended structural equation modeling framework. Psychometrika 76, 306-317.

Boomsma DI, Saviouk V, Hottenga JJ, Distel MA, De Moor MH, Vink JM, Geels LM, Van Beek JH, Bartels M, De Geus EJ, Willemsen G (2010). Genetic epidemiology of attention deficit hyperactivity disorder (ADHD index) in adults. PLOS ONE 5, e10621.

Brikell I, Kuja-Halkola R, Larsson H (2015). Heritability of attention-deficit hyperactivity disorder in adults. American Journal of Medical Genetics. Part B: Neuropsychiatric Genetics 168, 408-413.

Brogan A, Hevey D, Pignatti R (2010). Anorexia, bulimia, and obesity: shared decision making deficits on the Iowa Gambling Task (IGT). Journal of the International Neuropsychological Society 16, 711-715.

Bulik CM, Sullivan PF, Kendler KS (1998). Heritability of binge-eating and broadly defined bulimia nervosa. Biological Psychiatry 44, 1210-1218.

Bulik CM, Thornton LM, Root TL, Pisetsky EM, Lichtenstein P, Pedersen NL (2010). Understanding the relation between anorexia nervosa and bulimia nervosa in a Swedish national twin sample. Biological Psychiatry 67, 71-77.

Capusan AJ, Bendtsen P, Marteinsdottir I, Kuja-Halkola R, Larsson H (2015). Genetic and environmental contributions to the association between attention deficit hyperactivity disorder and alcohol dependence in adulthood: a large population-based twin study. American Journal of Medical Genetics. Part B: Neuropsychiatric Genetics 168, 414-422.

Capusan AJ, Bendtsen P, Marteinsdottir I, Larsson H (2016). Comorbidity of adult ADHD and its subtypes with substance use disorder in a large population-based epidemiological study. Journal of Attention Disorder. 2016 February 2 [Epub ahead of print]. doi:10.1177/ 1087054715626511. 
Carmona S, Hoekzema E, Ramos-Quiroga JA, Richarte V, Canals C, Bosch R, Rovira M, Soliva JC, Bulbena A, Tobena A, Casas M, Vilarroya O (2012). Response inhibition and reward anticipation in medication-naive adults with attention-deficit/hyperactivity disorder: a within-subject case-control neuroimaging study. Human Brain Mapping 33, 2350-2361.

Coghill DR, Seth S, Matthews K (2014). A comprehensive assessment of memory, delay aversion, timing, inhibition, decision making and variability in attention deficit hyperactivity disorder: advancing beyond the three-pathway models. Psychological Medicine 44, 1989-2001.

Cortese S, Bernardina BD, Mouren MC (2007a). Attentiondeficit/hyperactivity disorder (ADHD) and binge eating. Nutrition Reviews 65, 404-411.

Cortese S, Isnard P, Frelut ML, Michel G, Quantin L, Guedeney A, Falissard B, Acquaviva E, Dalla Bernardina B, Mouren MC (2007b). Association between symptoms of attention-deficit/hyperactivity disorder and bulimic behaviors in a clinical sample of severely obese adolescents. International Journal of Obesity (2005), 31, 340-346.

Davis C (2015). The epidemiology and genetics of binge eating disorder (BED). CNS Spectrums 20, 522-529.

Davis C, Patte K, Curtis C, Reid C (2010). Immediate pleasures and future consequences. A neuropsychological study of binge eating and obesity. Appetite 54, 208-213.

Davis C, Patte K, Levitan RD, Carter J, Kaplan AS, Zai C, Reid C, Curtis C, Kennedy JL (2009a). A psycho-genetic study of associations between the symptoms of binge eating disorder and those of attention deficit (hyperactivity) disorder. Journal of Psychiatric Research 43, 687-696.

Davis CA, Levitan RD, Reid C, Carter JC, Kaplan AS, Patte KA, King N, Curtis C, Kennedy JL (2009b). Dopamine for 'wanting' and opioids for 'liking': a comparison of obese adults with and without binge eating. Obesity 17, 12201225.

Edvinsson D, Bingefors K, Lindstrom E, Lewander T (2010). ADHD-related symptoms among adults in out-patient psychiatry and female prison inmates as compared with the general population. Upsala Journal of Medical Sciences 115, $30-40$.

Edwards AC, Kendler KS (2012). Twin study of the relationship between adolescent attention-deficit/ hyperactivity disorder and adult alcohol dependence. Journal of Studies on Alcohol and Drugs 73, 185-194.

Engel SG, Corneliussen SJ, Wonderlich SA, Crosby RD, Le Grange D, Crow S, Klein M, Bardone-Cone A, Peterson C, Joiner T, Mitchell JE, Steiger H (2005). Impulsivity and compulsivity in bulimia nervosa. International Journal of Eating Disorders 38, 244-251.

Faraone SV, Asherson P, Banaschewski T, Biederman J, Buitelaar JK, Ramos-Quiroga JA, Rohde LA, SonugaBarke EJ, Tannock R, Franke B (2015). Attention-deficit/ hyperactivity disorder. Nature Reviews Disease Primers 1, 15020.

Faraone SV, Biederman J, Doyle A, Murray K, Petty C, Adamson JJ, Seidman L (2006). Neuropsychological studies of late onset and subthreshold diagnoses of adult attention-deficit/hyperactivity disorder. Biological Psychiatry 60, 1081-1087.

First M, Spitzer RL, Gibbon M, Williams JBW (2002). Structured Clinical Interview for DSM-IV-TR Axis I Disorders, Research Version, Non-patient Edition. (SCID-I/NP), Biometrics Research, New York State Psychiatric Institute: New York.

Franke B, Faraone SV, Asherson P, Buitelaar J, Bau CH, Ramos-Quiroga JA, Mick E, Grevet EH, Johansson S, Haavik J, Lesch KP, Cormand B, Reif A (2012). The genetics of attention deficit/hyperactivity disorder in adults, a review. Molecular Psychiatry 17, 960-987.

Friedrichs B, Igl W, Larsson H, Larsson JO (2012). Coexisting psychiatric problems and stressful life events in adults with symptoms of ADHD - a large Swedish population-based study of twins. Journal of Attention Disorder 16, 13-22.

Furberg H, Lichtenstein P, Pedersen NL, Thornton L, Bulik CM, Lerman C, Sullivan PF (2008). The STAGE cohort: a prospective study of tobacco use among Swedish twins. Nicotine \& Tobacco Research 10, 1727-1735.

Gearhardt AN, Davis C, Kuschner R, Brownell KD (2011a). The addiction potential of hyperpalatable foods. Current Drug Abuse Reviews 4, 140-145.

Gearhardt AN, White MA, Potenza MN (2011b). Binge eating disorder and food addiction. Current Drug Abuse Reviews 4, 201-207.

Ginsberg Y, Hirvikoski T, Lindefors N (2010). Attention Deficit Hyperactivity Disorder (ADHD) among longer-term prison inmates is a prevalent, persistent and disabling disorder. BMC Psychiatry 10, 112.

Kessler RC, Adler L, Barkley R, Biederman J, Conners CK, Demler O, Faraone SV, Greenhill LL, Howes MJ, Secnik K, Spencer T, Ustun TB, Walters EE, Zaslavsky AM (2006). The prevalence and correlates of adult ADHD in the United States: results from the National Comorbidity Survey Replication. American Journal of Psychiatry 163, 716-723.

Kessler RC, Adler LA, Gruber MJ, Sarawate CA, Spencer T, Van Brunt DL (2007). Validity of the World Health Organization Adult ADHD Self-Report Scale (ASRS) Screener in a representative sample of health plan members. International Journal of Methods in Psychiatric Research 16, 52-65.

Larsson H, Asherson P, Chang Z, Ljung T, Friedrichs B, Larsson JO, Lichtenstein P (2013). Genetic and environmental influences on adult attention deficit hyperactivity disorder symptoms: a large Swedish population-based study of twins. Psychological Medicine 43, 197-207.

Larsson H, Chang Z, D'onofrio BM, Lichtenstein P (2014). The heritability of clinically diagnosed attention deficit hyperactivity disorder across the lifespan. Psychological Medicine 44, 2223-2229.

Levy F, Hay DA, Mcstephen M, Wood C, Waldman I (1997). Attention-deficit hyperactivity disorder: a category or a continuum? Genetic analysis of a large-scale twin study. Journal of the American Academy of Child and Adolescent Psychiatry 36, 737-744.

Lichtenstein P, De Faire U, Floderus B, Svartengren M, Svedberg P, Pedersen NL (2002). The Swedish Twin 
Registry: a unique resource for clinical, epidemiological and genetic studies. Journal of Internal Medicine 252, 184-205.

Lichtenstein P, Sullivan PF, Cnattingius S, Gatz M, Johansson S, Carlstrom E, Bjork C, Svartengren M, Wolk A, Klareskog L, De Faire U, Schalling M, Palmgren J, Pedersen NL (2006). The Swedish Twin Registry in the third millennium: an update. Twin Research and Human Genetics 9, 875-882.

Maclean A, Sweeting H, Walker L, Patterson C, Raisanen U, Hunt K (2015). 'It's not healthy and it's decidedly not masculine': a media analysis of UK newspaper representations of eating disorders in males. BMJ Open 5, e007468.

Martin J, Hamshere ML, Stergiakouli E, O'donovan MC, Thapar A (2014). Genetic risk for attention-deficit/ hyperactivity disorder contributes to neurodevelopmental traits in the general population. Biological Psychiatry 76, 664-671.

Mcloughlin G, Ronald A, Kuntsi J, Asherson P, Plomin R (2007). Genetic support for the dual nature of attention deficit hyperactivity disorder: substantial genetic overlap between the inattentive and hyperactive-impulsive components. Journal of Abnormal Child Psychology 35, 999-1008.

Mikami AY, Hinshaw SP, Patterson KA, Lee JC (2008). Eating pathology among adolescent girls with attentiondeficit/hyperactivity disorder. Journal of Abnormal Psychology 117, 225-235.

Mitchell KS, Neale MC, Bulik CM, Aggen SH, Kendler KS, Mazzeo SE (2010). Binge eating disorder: a symptom-level investigation of genetic and environmental influences on liability. Psychological Medicine 40, 1899-1906.

Moffitt TE, Houts R, Asherson P, Belsky DW, Corcoran DL, Hammerle M, Harrington H, Hogan S, Meier MH, Polanczyk GV, Poulton R, Ramrakha S, Sugden K, Williams B, Rohde LA, Caspi A (2015). Is adult ADHD a childhood-onset neurodevelopmental disorder? Evidence from a four-decade longitudinal cohort study. American Journal of Psychiatry 172, 967-977.

Murphy P, Schachar R (2000). Use of self-ratings in the assessment of symptoms of attention deficit hyperactivity disorder in adults. American Journal of Psychiatry 157, 11561159.

Mustelin L, Raevuori A, Hoek HW, Kaprio J, KeskiRahkonen A (2015). Incidence and weight trajectories of binge eating disorder among young women in the community. International Journal of Eating Disorders 48, 1106-1112.

Neale MC, Cardon LR (1992). Methodology for Genetic Studies of Twins and Families. Kluwer Academic Publishers: Dodrecht, Boston, London.

Nordsletten AE, Larsson H, Crowley JJ, Almqvist C, Lichtenstein P, Mataix-Cols D (2016). Patterns of nonrandom mating within and across 11 major psychiatric disorders. JAMA Psychiatry 73, 354-361.

Peterson CM, Baker JH, Thornton LM, Trace SE, Mazzeo SE, Neale MC, Munn-Chernoff MA, Lichtenstein P, Pedersen NL, Bulik CM (2016). Genetic and environmental components to self-induced vomiting. International Journal of Eating Disorders 49, 421-427.

Pettersson E, Larsson H, Lichtenstein P (2016). Common psychiatric disorders share the same genetic origin: a multivariate sibling study of the Swedish population. Molecular Psychiatry 21, 717-721.

Racine SE, Keel PK, Burt SA, Sisk CL, Neale M, Boker S, Klump KL (2013). Exploring the relationship between negative urgency and dysregulated eating: etiologic associations and the role of negative affect. Journal of Abnormal Psychology 122, 433-444.

Reichborn-Kjennerud T, Bulik CM, Tambs K, Harris JR (2004). Genetic and environmental influences on binge eating in the absence of compensatory behaviors: a population-based twin study. International Journal of Eating Disorders 36, 307-314.

Reinblatt SP, Leoutsakos JM, Mahone EM, Forrester S, Wilcox HC, Riddle MA (2015). Association between binge eating and attention-deficit/hyperactivity disorder in two pediatric community mental health clinics. International Journal of Eating Disorders 48, 505-511.

Root TL, Thornton LM, Lindroos AK, Stunkard AJ, Lichtenstein P, Pedersen NL, Rasmussen F, Bulik CM (2010). Shared and unique genetic and environmental influences on binge eating and night eating: a Swedish twin study. Eating Behaviors 11, 92-98.

Rosval L, Steiger H, Bruce K, Israel M, Richardson J, Aubut $\mathbf{M}$ (2006). Impulsivity in women with eating disorders: problem of response inhibition, planning, or attention? International Journal of Eating Disorders 39, 590-593.

Sandra Kooij JJ, Marije Boonstra A, Swinkels SH, Bekker EM, De Noord I, Buitelaar JK (2008). Reliability, validity, and utility of instruments for self-report and informant report concerning symptoms of ADHD in adult patients. Journal of Attention Disorder 11, 445-458.

Schulte EM, Grilo CM, Gearhardt AN (2016). Shared and unique mechanisms underlying binge eating disorder and addictive disorders. Clinical Psychology Review 44, 125-139.

Seitz J, Kahraman-Lanzerath B, Legenbauer T, Sarrar L, Herpertz S, Salbach-Andrae H, Konrad K, HerpertzDahlmann B (2013). The role of impulsivity, inattention and comorbid ADHD in patients with bulimia nervosa. PLoS ONE 8, e613891.

Seymour KE, Reinblatt SP, Benson L, Carnell S (2015). Overlapping neurobehavioral circuits in ADHD, obesity, and binge eating: evidence from neuroimaging research. CNS Spectrums 20, 401-411.

Shaw P, Stringaris A, Nigg J, Leibenluft E (2014). Emotion dysregulation in attention deficit hyperactivity disorder. American Journal of Psychiatry 171, 276-293.

Solanto MV, Abikoff H, Sonuga-Barke E, Schachar R, Logan GD, Wigal T, Hechtman L, Hinshaw S, Turkel E (2001). The ecological validity of delay aversion and response inhibition as measures of impulsivity in AD/HD: a supplement to the NIMH multimodal treatment study of AD/HD. Journal of Abnormal Child Psychology 29, 215-228.

Sonneville KR, Calzo JP, Horton NJ, Field AE, Crosby RD, Solmi F, Micali N (2015). Childhood hyperactivity/ inattention and eating disturbances predict binge 
eating in adolescence. Psychological Medicine 45, 2511-2520.

Sonuga-Barke EJ, Fairchild G (2012). Neuroeconomics of attention-deficit/hyperactivity disorder: differential influences of medial, dorsal, and ventral prefrontal brain networks on suboptimal decision making? Biological Psychiatry 72, 126-133.

Strother E, Lemberg R, Stanford SC, Turberville D (2012). Eating disorders in men: underdiagnosed, undertreated, and misunderstood. Eating Disorders 20, 346-355.

Surman CB, Randall ET, Biederman J (2006). Association between attention-deficit/hyperactivity disorder and bulimia nervosa: analysis of 4 case-control studies. Journal of Clinical Psychiatry 67, 351-354.

Trace SE, Baker JH, Penas-Lledo E, Bulik CM (2013a). The genetics of eating disorders. Annual Review of Clinical Psychology 9, 589-620.

Trace SE, Thornton LM, Baker JH, Root TL, Janson LE, Lichtenstein P, Pedersen NL, Bulik CM (2013b). A behavioral-genetic investigation of bulimia nervosa and its relationship with alcohol use disorder. Psychiatry Research 208, 232-237.
Trace SE, Thornton LM, Root TL, Mazzeo SE, Lichtenstein P, Pedersen NL, Bulik CM (2012). Effects of reducing the frequency and duration criteria for binge eating on lifetime prevalence of bulimia nervosa and binge eating disorder: implications for DSM-5. International Journal of Eating Disorders 45, 531-536.

Volkow ND, Wang GJ, Tomasi D, Baler RD (2013). The addictive dimensionality of obesity. Biological Psychiatry 73, 811-818.

Welch E, Jangmo A, Thornton LM, Norring C, Von Hausswolff-Juhlin Y, Herman BK, Pawaskar M, Larsson H, Bulik CM (2016). Treatment-seeking patients with bingeeating disorder in the Swedish national registers: clinical course and psychiatric comorbidity. BMC Psychiatry 16, 163. Willcutt EG, Nigg JT, Pennington BF, Solanto MV, Rohde LA, Tannock R, Loo SK, Carlson CL, Mcburnett K, Lahey BB (2012). Validity of DSM-IV attention deficit/ hyperactivity disorder symptom dimensions and subtypes. Journal of Abnormal Psychology 121, 991-1010.

Wu M, Hartmann M, Skunde M, Herzog W, Friederich HC (2013). Inhibitory control in bulimic-type eating disorders: a systematic review and meta-analysis. PLOS ONE 8, e83412. 